\title{
Denuncia y representación mediática de los sobrevivientes en la posdictadura: el caso de El Vesubio (1983-1984)
}

\author{
Denounce and media representation of the survivors during post- \\ dictatorship: ‘The Vesubio' case (1983-1984)
}

Rodrigo González Tizón el_taison@hotmail.com

http://orcid.org/0000-0003-2653-7028

Instituto de Altos Estudios Sociales; Universidad Nacional de San Martín/

Consejo de Investigaciones Científicas y Técnicas (Argentina)

\section{Resumen}

El retorno de la democracia en la Argentina se caracterizó por el debate sobre los modos de enjuiciar a los responsables de la violencia del pasado inmediato y por la difusión masiva de los crímenes de la dictadura en el espacio público local. En este contexto, se produjo la aparición pública de un actor central del activismo en derechos humanos, cuyo papel fue fundamental en la visibilización de los crímenes del período 1976-1983: los sobrevivientes de los centros clandestinos de detención. Este artículo aborda la experiencia de esta porción de las víctimas de la represión durante los dos primeros años de democracia a partir de los sobrevivientes de "El Vesubio", un lugar de detención ilegal ubicado en la provincia de Buenos Aires. A través del análisis de las acciones de denuncia realizadas por este grupo de sobrevivientes y del examen de las representaciones mediáticas de su figura, este trabajo pretende echar luz sobre el 
proceso histórico que condujo a la formación de una primera imagen pública de este segmento de las víctimas de la represión, asociada a la figura del testigo.

Palabras clave: Sobrevivientes; centros clandestinos de detención; posdictadura; testigo; medios de comunicación.

\section{Abstract}

The return of democracy in Argentina was characterized by the discussion about the ways of judging the responsables of the recent past violence and the massive diffusion of the dictatorship crimes in the local public space. In this context, took place the public appearance of one of the most important actors of the human rights activism, whose role was fundamental in the process of making visible the crimes of the 1976-1983 period: the survivors of the clandestine detention centers. This articles studies the experience of this portion of the repression victimes during the first two years of democracy by examining the case of 'The Vesubio' survivors, an ilegal detention center located in Buenos Aires. Through the analysis of the denounce actions made by that group of survivors and the examination of the media representations of their figure, this work aims tu iluminate the historical process that led to the formation of the first public image of that segment of the repression victims, associated with the witness figure.

Key words: Survivors; clandestine detention centers; post-dictatorship; witness; media

La defensa de los derechos humanos se convirtió, hacia el final de la dictadura, en la principal consigna de Raúl Alfonsín en su carrera hacia la presidencia (Franco, 2016; Landi y González Bombal, 1995). Una vez electo presidente, el mandatario emprendió una serie de iniciativas para cumplir con su promesa de campaña. El primer paso fue derogación de la Ley de Autoamnistía Nro. 22924, sancionada por los militares para evitar un posterior proceso judicial. A ello se sumó, el 13 de diciembre de 1983, la sanción del Decreto 158, por el cual se establecía el procesamiento de las tres primeras juntas militares (1). Finalmente, a través del Decreto 187/83, el Ejecutivo Nacional avanzó con la creación de una comisión de "notables" para investigar la represión dictatorial: la Comisión Nacional sobre la Desaparición de Personas (CONADEP). En un momento en que se discutía cómo debía realizarse el enjuiciamiento de los 
crímenes del pasado inmediato, Alfonsín pretendía mostrar el compromiso estatal con la condena de la represión, en un intento por clausurar definitivamente la dictadura y sentar las bases de un nuevo orden político basado en la democracia y los derechos humanos (Crenzel, 2008; Landi y González Bombal, 1995; Vezzetti, 2002).

El restablecimiento de la democracia fue acompañado de la visibilización masiva de los crímenes dictatoriales, hasta entonces celosamente ocultos de la esfera pública nacional por la censura militar. A fines de 1983 y en los primeros meses de 1984, se difundió a través de la prensa local, de forma masiva y sensacionalista, información e imágenes del hallazgo de cadáveres, fosas comunes y supuestos lugares de detención, así como también relatos sobre la tortura y el cautiverio ilegal. Este fenómeno fue bautizado por los contemporáneos como un "show del horror", en alusión al tinte morboso de las noticias (Feld, 2004 y 2015; Landi y González Bombal, 1995). En este clima político se produjo la emergencia pública de un actor que, a pesar de su rol en la denuncia durante la dictadura (González Tizón, 2016; Tello, 2015), no había gozado hasta entonces de visibilidad dentro de la Argentina: los sobrevivientes de los Centros Clandestinos de Detención (CCD).

Este artículo realiza un abordaje histórico de este segmento de las víctimas de la represión durante la posdictadura (2) desde una doble dimensión: examina, por un lado, las iniciativas de denuncias desarrolladas por los sobrevivientes para visibilizar los crímenes dictatoriales y, por el otro, las representaciones mediáticas de su figura. Todo esto, a partir del análisis de un caso particular: el de los sobrevivientes del CCD El Vesubio (3). De este modo, se pretende contribuir a la comprensión histórica de uno de los actores centrales del movimiento de derechos humanos argentino.

Los sobrevivientes de los CCD se convirtieron, sobre todo recientemente, en objeto de reflexión de investigaciones del campo de las ciencias sociales. La mayoría de esos trabajos se dedicaron a examinar diversos aspectos vinculados con su práctica testimonial (Dürr, 2017; Feld y Messina, 2014; Forcinito, 2014; Lampasona, 2011; Messina, 2012 y Tello, 2015). Otros, en cambio, indagaron en las dificultades atravesadas por los sobrevivientes durante su reinserción social, ya sea por las impugnaciones recibidas desde los círculos militantes (Longoni, 2007) como por las complejidades del propio proceso de "reaparición" (Rama, 2017). En relación con el papel de los sobrevivientes en la posdictadura, estos fueron incluidos como parte de una reflexión mayor sobre los modos de representación de la violencia dictatorial en la escena pública (Feld, 2004, 2014 y 2015). No se registran, en cambio, investigaciones abocadas a una reflexión sistemática sobre las modalidades de denuncia desplegadas por los sobrevivientes más allá de la producción de relatos sobre el cautiverio, ni al examen específico 
del proceso de construcción de su figura pública desde una perspectiva histórica. Esta investigación se propone contribuir a llenar esa vacancia.

La etapa seleccionada resulta especialmente fructífera para el análisis propuesto, ya que fue durante los primeros meses de democracia cuando, al mismo tiempo que se multiplicaron sus acciones de denuncia, se produjo su emergencia en el espacio público nacional. En un escenario signado por los intentos de sacar a la superficie la "verdad" sobre los crímenes de la dictadura, los sobrevivientes de El Vesubio realizaron diversos intentos por sacar a la luz lo sucedido en ese CCD. Mientras lo hacían, se vieron solicitados constantemente desde su condición de productores de relatos sobre el dispositivo represivo. Ambas facetas del accionar de denuncia de los sobrevivientes se vieron representadas en el espacio público de la posdictadura. Los primeros pasos en la construcción de una verdad estatal sobre la violencia dictatorial marcaron, sin embargo, el quiebre de esa ambigüedad. A partir de entonces, y de manera cada vez más pronunciada, la imagen de los sobrevivientes en el espacio público se vería reducida a una única faceta de su accionar: la producción de relatos sobre el cautiverio clandestino. O, lo que es lo mismo, su condición de testigos del dispositivo represivo.

\section{Entre la denuncia y el "hallazgo": los sobrevivientes y el "show del horror"}

El 6 de diciembre de 1983, el juez de instrucción Carlos Oliveri ordenó realizar una inspección judicial en un predio situado en la intersección de la autopista Ricchieri con el Camino de Cintura, en el partido de La Matanza. El magistrado, titular del Juzgado Nacional de Primera Instancia en lo Criminal de Instrucción Nro. 3, tomaba la medida en el marco de la causa Nro. 35040, iniciada en julio de 1978 por el secuestro de una pareja de docentes (4). La medida respondía a una presentación realizada el día anterior por un grupo de personas, algunas de ellas citadas como testigos en la causa, quienes afirmaban haber ubicado el lugar donde habían permanecido secuestradas durante la dictadura.

Los denunciantes pertenecían -o lo habían hecho hasta poco tiempo antes- al Partido de la Liberación (PL), una agrupación de orientación maoísta creada a comienzos de la década de 1960 (5). Con el apoyo de las autoridades partidarias y del Centro de Estudios Legales y Sociales (CELS), organizaron una conferencia de prensa para difundir la noticia de la identificación del CCD. El evento, al que asistieron numerosos periodistas, recibió una importante difusión mediática en la prensa gráfica. De este modo, El Vesubio hacía su aparición en la escena pública local. 
Siguiendo a Feld (2004), la prensa fue el principal canal de difusión de la violencia del pasado inmediato durante los primeros meses de democracia. Ante la ausencia de una narración estatal sobre los crímenes dictatoriales, los medios de comunicación gráficos llevaron adelante "la construcción y la legitimación de una 'verdad' sobre los hechos del pasado" (Feld, 2004: 104). La inexistencia de un lenguaje específico para referir la masacre dictatorial condujo al empleo de fórmulas ya conocidas, procedentes en su mayoría de la sección "policiales". Esto les imprimió a las noticias sobre la represión el tinte sensacionalista que le valió su calificación en los términos de un "show del horror", cuyos protagonistas excluyentes fueron los cadáveres $\mathrm{NN}$ y las fosas comunes que los albergaban.

Los artículos que se hicieron eco de la identificación del predio de El Vesubio, publicados en diversos periódicos de tirada nacional, enfatizaron el componente de denuncia detrás de la ubicación del predio de Ricchieri y Camino de Cintura: "Denuncian la ubicación de un campo de detención clandestino"; "Denuncian localización de campo de detención y tortura camino a Ezeiza"; "Denunciaron la existencia de un 'campo de detención"', fueron algunos de los encabezados elegidos (Clarín, Crónica, Tiempo Argentino, 10 de diciembre de 1983). El contenido de las noticias mantenía el tono de los titulares: en todos los artículos se daba amplia cobertura a la denuncia judicial realizada por un grupo de personas que aseguraban haber estado cautivas en el predio inspeccionado. La representación del suceso se corría, de este modo, de los cánones que modelaron de forma general las referencias a la identificación de diversos CCD, en las que la noticia era presentada como un "hallazgo" (Feld, 2004).

Para entender esta particularidad en la cobertura mediática del acontecimiento de la ubicación de El Vesubio, es imprescindible considerar el trabajo previo realizado por los sobrevivientes de ese CCD vinculados a Vanguardia Comunista (VC) -nombre original del PL- para visibilizar los crímenes cometidos contra militantes del partido en ese lugar de cautiverio. Junto a familiares de sus compañeros desaparecidos y a organismos de derechos humanos locales, los sobrevivientes desarrollaron una intensa labor de investigación que, finalmente, desembocó en la identificación del lugar exacto del CCD, entonces demolido. Todo ese conocimiento acumulado durante los años de dictadura fue puesto a disposición de los medios durante la conferencia de prensa a través de un documento, cuyo contenido se volcó -por momentos de forma textual- en los artículos periodísticos, imprimiéndoles el tono denuncialista.

Los sobrevivientes ocupaban un rol protagónico en los artículos, que señalaban su importancia para la ubicación del lugar de cautiverio. La Gaceta afirmaba que el predio había sido "identificado por 35 prisioneros que resultaron liberados luego de haber permanecido en cautiverio" (10/12/1983). Clarín, en cambio, optaba por citar la voz de los sobrevivientes, que 
era así lanzada a un primer plano. Las palabras pertenecían a Jorge Watts, uno de los firmantes de la denuncia:

La certeza de que el lugar es éste (...) parte de los mosaicos nada comunes, de que yo llegué a ver las vías ferroviarias que desde aquí se aprecian nítidamente, la parada del colectivo 86 del que sólo ascendía o descendía personal uniformado, la existencia de una pileta de natación hoy rellenada pero de la que conocíamos su existencia (Clarín, 10 de diciembre de 1983).

Las imágenes que acompañaban el texto también destacaron el protagonismo de los sobrevivientes. La misma fotografía era reproducida en los distintos periódicos: cuatro hombres en medio de un descampado, rodeados de escombros (Crónica, La Gaceta, La Razón, Tiempo Argentino, 10 de diciembre de 1983). Los epígrafes restituían las coordenadas que daban sentido a la imagen. Tiempo Argentino indicaba que "cuatro liberados muestran los escombros del lugar donde fueron detenidos" (10 de diciembre de 1983). Crónica, por su parte, intentaba otorgarle mayor encarnadura al proceso incluyendo los nombres de los sobrevivientes: "Darío Machado, Jorge Watts, Juan Frega y Guillermo Lorusso recorren el campo clandestino donde fueron torturados", afirmaba el texto que acompañaba la fotografía (Crónica, 10 de diciembre de 1983). La centralidad de los sobrevivientes contrastaba, por ejemplo, con el desinterés de la prensa por los funcionarios judiciales que habían participado del procedimiento en El Vesubio. La inestabilidad de las categorías y el vocabulario empleados para nominar los crímenes de la dictadura, recurrente en las intervenciones públicas durante la posdictadura (Feld y Franco, 2015), se manifestó en las primeras noticias sobre El Vesubio. Términos como "prisioneros", "presos políticos" o "liberados" eran utilizados indistintamente para hacer referencia a quienes habían salido con vida del CCD. En cambio, no se utilizaba la palabra "sobrevivientes". Lo mismo sucedía con las referencias al lugar de detención, al que se aludía sin distinciones como "campo de detención y tortura de detenidos-desaparecidos", "campo clandestino de detención" o, siguiendo el léxico de los propios represores, "chupadero" (Crónica, La Gaceta, La Razón, Tiempo Argentino, 10 de diciembre de 1983).

El detalle de las torturas aplicadas en El Vesubio fue otro de los tópicos aludidos, acorde con la lógica del "destape" que orientó a la prensa en los comienzos de la democracia (Feld, 2004). La Gaceta afirmaba que "Ios liberados dieron cuenta de 'dramáticos detalles de la aplicación de golpes, descargas eléctricas, estiramientos y torsiones (de miembros), simulacros de asfixia con bolsas de polietileno, amenazas a familiares, colocación de ratas sobre el cuerpo (de los 
torturados) (...)"'. Clarín, por su parte, reprodujo un fragmento del relato ofrecido por uno de los sobrevivientes, Jorge Watts, durante la conferencia de prensa, en el que afirmaba que "a causa de la tortura, que era indiscriminada, perdí varios dientes" porque "me daban a morder un hierro para evitar mis gritos en el momento en que me picaneaban" (Clarín, 10 de diciembre de 1983).

Las noticias periodísticas sobre El Vesubio continuaron, de manera moderada, durante diciembre de 1983 y a lo largo del año siguiente. En esto tuvieron mucho que ver las nuevas autoridades de la provincia de Buenos Aires. Las noticias sobre la existencia de un supuesto CCD en La Matanza llegaron a oídos del gobernador, Alejandro Armendáriz, quien ordenó a su Ministro de Gobierno iniciar las indagaciones correspondientes para corroborar la veracidad de la información publicada en la prensa. La denuncia del funcionario dio pie al inicio de nuevas actuaciones por los crímenes de El Vesubio: la causa Nro. 1800, con sede en el Juzgado Penal Nro. 7, Secretaría Nro. 13 de Morón, a cargo del Dr. Alfredo Ruiz Paz. Este nuevo impulso a la vía judicial, que se sumó a la pesquisa llevada adelante por el Dr. Oliveri, repercutió directamente en los sobrevivientes de EI Vesubio, que vieron en el terreno legal una vía para la denuncia de la represión.

\section{El diseño de una estrategia de denuncia en los albores de la democracia}

El 29 de diciembre de 1983 llegó al juzgado del Dr. Oliveri un escrito con las firmas de un conjunto de sobrevivientes de El Vesubio, los mismos que a comienzos de mes habían participado de la inspección ocular en el predio de Ricchieri y Camino de Cintura. El documento proponía incorporar a la investigación judicial de los casos de los miembros del partido que todavía permanecían en condición de desaparecidos. El texto llevaba, además de las firmas de los sobrevivientes, las de la mayoría de los familiares de los desaparecidos del partido, junto a las de los abogados del CELS. Una copia del mismo sería presentada también ante el juzgado a cargo del Dr. Ruiz Paz.

La denuncia tuvo pronta repercusión en una prensa proclive a difundir las noticias vinculadas con la represión dictatorial: La Razón (29 de diciembre de 1983 y 30 de diciembre de 1983; Crónica (29 de diciembre de 1983 y 30 de diciembre de 1983); Crónica (30 de diciembre de 1983); Diario Popular (30 de diciembre de 1983); La Prensa (30 de diciembre de 1983); La Razón (30 de diciembre de 1983) y La Voz (30 de diciembre de 1983) dedicaron espacio en sus páginas a la presentación. Con algunas variaciones menores, los artículos reproducían la 
información contenida en el escrito presentado ante el juez, reponiendo algunos de los datos aportados por los denunciantes en relación con El Vesubio: nombres de desaparecidos, apodos y nombres de represores, detalles sobre las torturas infligidas a los cautivos, entre otros. La Voz y Tiempo Argentino adjuntaban la misma fotografía para ilustrar los artículos: dos de los firmantes del documento eran retratados en las escalinatas de los Tribunales porteños, con la denuncia en sus manos, instantes antes de presentarla. Los sobrevivientes, nuevamente, eran señalados por la prensa como los impulsores de la investigación en ciernes. El escrito propiamente dicho iniciaba con una reconstrucción del caso de los militantes de VC secuestrados en El Vesubio. Se denunciaba el secuestro ilegal de "un grupo de más de 60 personas", cuyas detenciones habían sido "sistemáticamente negadas en cada una de las acciones judiciales emprendidas" (Juzgado Penal 7, 1983: 191). El texto, luego, relataba la diversa suerte corrida por ese contingente, repartida entre la liberación en la vía pública, la legalización o la desaparición. A continuación, se realizaba el pedido que había motivado el escrito, dirigido directamente al juez:

\footnotetext{
Vd. investiga en esta causa los ilícitos cometidos en perjuicio de muchos de los integrantes de los dos primeros grupos aludidos precedentemente [en referencia a los secuestrados liberados en la vía pública y a los legalizados], inclusive los que afectaron a algunos de los que suscriben esta denuncia.

(...) suficientes elementos nos llevan a concluir que el tercer grupo, compuesto por personas cuya privación ilegal de la libertad continúa hasta la fecha, fue arrestado por el mismo personal que intervino en los ilícitos que Vd. investiga en esta causa. Por lo tanto entendemos, por un principio de economía procesal, que Vd. también es competente para investigar en los mismos (Juzgado Penal 7, 1983: 189).
}

Lo novedoso de la presentación consistía no tanto en el pedido puntual -ya que una demanda similar se había realizado en 1980 - sino en la estrategia utilizada para realizarlo y en sus resultados. Apelando a un instrumento del mundo judicial, el principio de economía procesal, los sobrevivientes pretendían que el juez incorporara dentro de la causa que investigaba su secuestro y cautiverio la indagación sobre la desaparición del conjunto de los militantes del PL desaparecidos en El Vesubio, pedido al que el juez terminaría accediendo. En el nuevo contexto, las herramientas del derecho se convertían en aliadas fundamentales para los miembros del movimiento de derechos humanos, incluidos los sobrevivientes, siempre y cuando su pasado no estuviera vinculado a la militancia armada. 
El nuevo documento aportaba, además, información sobre el funcionamiento del dispositivo represivo dictatorial. La sección "Descripción de los secuestros" recuperaba, cuando era posible, las circunstancias en que cada uno de los desaparecidos había sido secuestrado. Las reconstrucciones mostraban un marcado estilo judicial, cuya huella más evidente era la apelación a la figura del testigo ocular: los testimonios de familiares, vecinos y transeúntes presentes durante los operativos de secuestro se configuraban, a lo largo de todo el apartado, como el insumo principal de la denuncia.

Las últimas tres secciones estaban dedicadas a la reconstrucción del entramado represivo con centro en El Vesubio, completando así los aportes realizados por los sobrevivientes en tiempos de dictadura. A las precisiones sobre la ubicación del lugar de cautiverio, seguía una reflexión respecto a la articulación entre los aparatos represivos legal y clandestino. Insinuada en los testimonios producidos durante el período dictatorial, dicha relación era denunciada de forma explícita en el nuevo escenario político. "Las unidades 'legales' de detención" sostenían que:

\begin{abstract}
Todos los detenidos retirados del centro clandestino de detención y tortura, fueron sometidos a un mismo procedimiento. En efecto, fueron abandonados en vehículos, encapuchados y maniatados, cerca de unidades militares. Las declaraciones de las víctimas, las circunstancias del procedimiento y el marco descripto, generan la condición de que existió un vínculo de conocimiento y, más aún, una coordinación entre el personal -o parte de él- que actuaba en el centro y el personal -parte de él- que operó en la "recepción" en las unidades militares (Juzgado Penal 7, 1983: 202).
\end{abstract}

En un contexto en el que el juicio a los responsables de la represión era una posibilidad concreta, el caso de El Vesubio parecía reunir todas las condiciones para probar uno de los argumentos centrales del movimiento de derechos humanos sobre la lógica de la represión dictatorial: la responsabilidad de los altos mandos militares en el ejercicio de los secuestros, las torturas, las muertes y las desapariciones. Así, pretendían refutar la idea de que esos crímenes constituían episodios aislados, producto de "excesos" de subordinados (Canelo, 2008) señalando, por el contrario, que eran el fruto de un plan pergeñado desde la cima de la jerarquía castrense.

El apartado "Las unidades aledañas al centro clandestino de detención" mencionaba las diversas dependencias policiales y militares vecinas a El Vesubio, pertenecientes al Ejército y a la provincia de Buenos Aires (PBA). A propósito de estas unidades se planteaban una serie de interrogantes: "¿puede ser que el titular y personal superior (...) ignoraran la existencia de ilícitos, reiteradamente cometidos, en inmuebles erigidos a escasa distancia?". Y, más 
concretamente, "¿podía ignorar el mencionado personal cuál era el uso que se le daba al 'centro"'? (Juzgado Penal 7, 1983: 202). Los estrictos controles a los que era sometida la zona por esas mismas fuerzas hacían difícil una respuesta negativa.

Para finalizar, en lo que constituía una de las novedades en el plano de la denuncia judicial, los cinco sobrevivientes que encabezaban la denuncia reclamaban su reconocimiento como querellantes en la causa que los tenía como damnificados. El reclamo podía pensarse hasta cierto punto como la expresión formal del cambio de roles que había comenzado a producirse en el tramo final de la dictadura al calor del resquebrajamiento del régimen militar, por el cual los antiguos acusados asumían paulatinamente el rol de acusadores, y viceversa.

En paralelo a las acciones en el terreno judicial, los sobrevivientes vinculados al PL desarrollaron iniciativas en el espacio público con el objetivo de visibilizar los crímenes de El Vesubio. Así, el 28 de abril de 1984 se llevó adelante la primera actividad pública frente al predio donde había funcionado el CCD. Jorge Watts, uno de los sobrevivientes que participó de la organización del evento, recuerda que:

hicimos una marcha de la rotonda de San Justo hasta El Vesubio, y vinieron todos los dirigentes de derechos humanos: ahí de La Matanza estaba el padre del Pablo Pimentel, que era un gordo fundador de la APDH (...). A esa marcha vino Pérez Esquivel, vino la gente que después estuvo en la CONADEP. Realmente, una marcha muy grande, vino mucha gente (...) calculo por lo menos cinco mil personas, un acto muy grande. Movilizaron todos los partidos (Jorge Watts, comunicación personal, 23 de marzo de 2015).

Si bien la afirmación de que "movilizaron todos los partidos" suena exagerada, e inexacta la referencia a la CONADEP -que entonces ya funcionaba-, lo cierto es que en la marcha se dio cita un variado espectro de fuerzas políticas. Según un informe realizado por la Unidad Regional XV de La Matanza para el Dr. Ruiz Paz, se hicieron presentes la Asamblea Permanente por los Derechos Humanos de La Matanza (APDH-Matanza), el Movimiento Al Socialismo (MAS), el Partido Intransigente (PI), Intransigencia y Movilización Peronista (lyM), el Peronismo Revolucionario (PR), la Federación Juvenil Comunista (FJC), el Partido Obrero (PO y el Frente de Izquierda Popular (FIP) (Juzgado Penal 7, 1983: 849). De los nombres de las agrupaciones se sigue que la convocatoria se circunscribió en lo esencial a fuerzas relacionadas con el arco progresista y al activismo por los derechos humanos.

El mismo informe disminuía el número de participantes de los cinco mil que señala Watts a trescientos cincuenta. La columna, nucleada en torno a la rotonda de San Justo, partió a las 17 horas hacia el predio de El Vesubio, donde tendría lugar el acto central. Portaban banderas con 
diferentes leyendas, entre las que se destacaban las de "Aparición con vida de los desaparecidos" y "Castigo y juicio a los culpables", consignas que condensaban reclamos originados en la etapa dictatorial con exigencias de la hora, vinculadas a las posibilidades abiertas con el retorno democrático (Ídem).

Los organismos de derechos humanos fueron los que tomaron la palabra en el acto central. Uno de los oradores principales fue Augusto Conte Mc Donnell, miembro fundador del CELS y por entonces diputado nacional, quien conocía en profundidad la represión en El Vesubio dado su trabajo con los sobrevivientes de VC en la dictadura. También habló la presidenta de la APDH-Matanza, Adela Soto, quien se refirió a la investigación en curso por los crímenes en ese CCD. Luego fue el turno de Luis Pimentel, en ese momento presidente del CELS. La última alocución estuvo a cargo de Arturo Vázquez, miembro del PI. El acto se cerró con la colocación simbólica de una placa en la que se denunciaban los crímenes cometidos en el lugar y con el encendido de una veintena de antorchas (Ídem).

Otra modalidad de denuncia que cobró fuerza durante la posdictadura fueron los "homenajes" a los desaparecidos de El Vesubio. Watts, también vinculado a la organización de esos actos, recuerda que el primero de esos homenajes se hizo "en el mismo año 79", y que se difundió solamente "a los familiares y amigos" (Jorge Watts, comunicación personal, 23 de marzo de 2015). Realizados en forma clandestina, los homenajes nacieron como una forma de recordar a los desaparecidos del PL en tiempos de dictadura. Con la democracia, estos actos alcanzaron mayor publicidad e incorporaron a otras víctimas de El Vesubio más allá de las fronteras del partido. Así, los homenajes cumplieron no sólo con el objetivo de visibilizar a los desaparecidos dicho CCD de un modo general, sino que además se convirtieron en ámbito de reunión para sobrevivientes, familiares y allegados sin vínculos con la militancia en el PL.

Otra iniciativa de denuncia implementada en la posdictadura y que, al igual que los homenajes, remontaba sus orígenes al último tramo del período dictatorial, fue la publicación de solicitadas en periódicos nacionales. EL 29 de septiembre de 1984, al cumplirse el sexto aniversario del secuestro de los militantes del PL, el grupo de sobrevivientes y familiares vinculado al partido publicó una solicitada en el diario Clarín. El escrito tomaba prestado su título del flamante informe de la CONADEP, que había visto la luz ese mismo mes: "Nunca más", rezaba el encabezado en letra negrita (Clarín, 29 de septiembre de 1984). En el objetivo conmemorativo se mezclaba la solicitada con la pretensión de incidir en el curso los acontecimientos políticos de la época. Se denunciaban las maniobras desplegadas por los actores castrenses en el terreno judicial para remitir los juicios por los crímenes dictatoriales a la órbita de la justicia militar, reivindicando la competencia de los tribunales civiles. Como sostén de su reclamo, los 
autores de la solicitada sacaban a relucir las diversas gestiones realizadas durante la dictadura y los inicios de la democracia para denunciar los crímenes en El Vesubio:

a) La acumulación de pruebas ante la justicia civil; b) las declaraciones de decenas de víctimas de El Vesubio que recuperaron su libertad; c) las confesiones de miembros de las fuerzas de seguridad que operaron en ese antro; d) la constatación de que ahí fueron aherrojadas y continúan desaparecidas un centenar de personas, incluso niños; e) la comprobación de que allí operaron Ejército, Policía de la Pcia. de Bs. Aires, Ser. Penintenciario Nacional y colaboró Policía Federal; f) nuestra solicitud de procesamiento a 18 jefes de las Fuerzas Armadas (Clarín, 29 de septiembre de 1984).

La enumeración ofrecía un buen repaso de la trayectoria del colectivo de denuncia impulsado por los sobrevivientes del PL durante la dictadura. El texto de la solicitada, a su vez, dejaba entrever los avances de la investigación sobre los crímenes en El Vesubio en los primeros meses de la posdictadura más allá de dicho núcleo inicial: el "centenar de personas" desaparecidas al que aludía el escrito excedía con mucho a los militantes del partido víctimas de la represión. Esta incorporación de nuevos nombres a la lista de desaparecidos, algunos de los cuales se conocían ya en dictadura, ocurría en paralelo a un fenómeno que tenía lugar al interior del actor sobreviviente: la incorporación de "nuevos" hombres y mujeres que, venciendo el temor a posibles represalias, rompían el silencio y testimoniaban ante alguna de las instancias dispuestas a tales fines. De este modo, se producía una ampliación del universo sobreviviente, que trascendía así de las fronteras del partido.

\section{El testimonio como mandato: el documental Nunca más}

El 4 de julio de 1984, Canal 13 -entonces estatal- subió al aire un programa con los resultados preliminares de la investigación de la CONADEP. Los crímenes dictatoriales llegaban por fin a la televisión, alcanzando una difusión desconocida hasta entonces. La emisión del documental estuvo rodeada de una enorme tensión por la reacción negativa que podría generar en los militares, motivando discusiones en el seno del gobierno. Sin embargo, la presión de los propios miembros de la CONADEP, sumada a la de los organismos de derechos humanos, terminó de torcer la balanza a favor de la realización del programa (Crenzel, 2008).

La emisión otorgó un lugar protagónico a los afectados por la represión, que con sus relatos se convirtieron en los portavoces de la masacre dictatorial. Junto a los familiares de los 
desaparecidos, estaban los sobrevivientes de los CCD, convocados a participar del documental para dar testimonio de su cautiverio clandestino. Entre los dos sobrevivientes invitados se encontraba Watts, quien fuera contactado por la periodista Magdalena Ruiz Guiñazú, miembro de la CONADEP e impulsora del programa (Jorge Watts, comunicación personal, 23 de marzo de 2015).

Por pedido de Alfonsín, la apertura del programa estuvo a cargo del Ministro del Interior, Antonio Tróccoli. Se buscaba así moderar un efecto de condena unilateral hacia los miembros de las Fuerzas Armadas como producto de la abrumadora evidencia recogida sobre los crímenes cometidos durante la dictadura. Tróccoli comenzó afirmando que el contenido del documental era "sólo un aspecto del drama de la violencia en Argentina" y que "la otra cara, el otro aspecto, se inició cuando recaló en las playas argentinas la irrupción de la subversión y del terrorismo". Estos subversivos, en su afán por hacerse del poder del Estado, habían desatado "una orgía de sangre y de muerte" que había envuelto a la sociedad entera (CONADEP, 2010). Las palabras del funcionario recogían lo esencial del imaginario antisubversivo forjado en los años previos a la dictadura, que demostraba su vigencia en la etapa democrática (Franco, 2012 y 2015). Tróccoli le agregaba, sí, la condena del accionar represivo de las Fuerzas Armadas, en una fórmula que excluía de culpa y cargo al conjunto social: "lo que menos podía presuponer esta misma sociedad [al reclamar la intervención a los militares]", sostenía el ministro, "es que el propio Estado iba a adoptar metodologías del mismo signo, tan aberrantes como las que acababa de impugnar y que habían sido utilizadas por la subversión y el terrorismo" (CONADEP, 1984). Quedaban expuestos así los fundamentos de lo que, a instancias de los organismos de derechos humanos, se conocería como la "Teoría de los dos demonios" (Franco, 2015).

El final de la intervención de Tróccoli daba paso al documental. Una voz en off realizaba una descripción veloz de los aspectos fundamentales de la represión dictatorial, incluyendo cifras de las víctimas y referencias a los lugares de cautiverio, a lo que seguía una reivindicación de la labor de la CONADEP. El tono elogioso se extendía después hacia los denunciantes: el éxito de la tarea emprendida por la Comisión, sostenía la voz en off,

sólo pudo ser posible merced a la valentía, al coraje único de hombres y mujeres que no callaron, a quienes les atormentaron los cuerpos pero no pudieron sujetar sus mentes y que hoy posibilitan esta búsqueda esperanzada de justicia y de verdad (CONADEP, 1984). 
La frase daba pie a los testimonios de los protagonistas, cuyo dramatismo se veía acentuado por la puesta en escena realizada: un estudio en penumbras, iluminado apenas por una luz tenue, en el cual sólo era posible observar una tarima y ocho sillas. En cada una de las ellas se divisaba una silueta. Una melodía acorde con la escenografía acompañaba el plano general. El cuadro, estático, se interrumpió con el primero de los relatos, a cargo de Enrique Fernández Meijide, padre de un joven desaparecido y miembro de la Asamblea Permanente por los Derechos Humanos (APDH). La cámara ofrecía un primer plano de su rostro, iluminado por una luz focal que tornaba reconocibles sus facciones. Finalizada la intervención, la cámara volvía a tomar el plano general mientras la escena iba poniéndose paulatinamente a oscuras.

Luego de un breve corte, la voz en off proponía una reflexión acerca de los dichos de los militares sobre la naturaleza de la represión. Imágenes aéreas de la ciudad, otras sobre el Mundial de fútbol de 1978 y, en el cierre, una visual del microcentro y las autopistas porteñas, acompañaban la crítica de diversos aspectos de la dictadura: la amplitud y arbitrariedad de la represión, los intentos de disuadir a la opinión pública respecto de los secuestros y desapariciones, la especulación financiera y los gastos exorbitantes del Estado, respectivamente. Y detrás de todo ello, sentenciaba la voz en off, "8800 desaparecidos; 8800 silencios" (CONADEP, 1984). La imagen volvía entonces al estudio, donde rápidamente la cámara hacía un primer plano de la cara de Watts, quien enseguida iniciaba su testimonio.

La alocución comenzaba con una reconstrucción del secuestro y del posterior traslado "a un predio ubicado en Camino de Cintura y Richieri, conocido hoy como El Vesubio, un campo clandestino de detención que dependía del primer cuerpo del Ejército" (CONADEP, 1984). A continuación, Watts ofrecía una descripción del predio, incluyendo sus medidas aproximadas, y una indicación de su pertenencia al Servicio Penitenciario Federal (SPF).

En seguida, el relato se enfocó en la descripción pormenorizada de las torturas. Primero, de las sufridas en carne propia, las cuales habían incluido tanto el castigo físico como el psicológico. Luego, el eje del discurso se corría a los suplicios aplicados a otros secuestrados, y que Watts había presenciado durante su estadía en El Vesubio. Resaltaba puntualmente dos casos: el de un hombre asesinado a golpes por los represores y el de una mujer que había perdido su embarazo a causa de las torturas recibidas. A ello le sumaba la denuncia de las violaciones de algunas cautivas por parte de los oficiales encargados del lugar.

La descripción del procedimiento de legalización de secuestrados en El Vesubio fue otro de los tópicos abordados. Al igual que en la solicitada, la denuncia trascendía los límites partidarios, en un intento por dar cuenta de la magnitud alcanzada por la represión en El Vesubio: "por este lugar han pasado infinidad de personas, calculo cientos y tal vez más de mil personas en los 
tres años que, según las investigaciones realizadas por la justicia, ha funcionado en ese lugar" (CONADEP, 1984). Sin explicitarlo, el testimonio de Watts dejaba entrever el trabajo de indagación previo realizado por el colectivo forjado en torno al PL para reconstruir el entramado represivo de El Vesubio.

El relato finalizaba con unas palabras dirigidas a los espectadores: "yo creo que los que tenemos este raro privilegio de haber pasado por este infierno y tener la posibilidad de contarlo ante ustedes tenemos la obligación, el deber de dar testimonio de esto, de no callarnos la boca para que, efectivamente, esto no suceda más" (CONADEP, 1984, el subrayado es del autor). Watts explicitaba así un supuesto "deber de memoria" de los sobrevivientes, una suerte de mandato constitutivo del haber salido con vida del cautiverio clandestino. El sobreviviente era, antes que cualquier otra cosa, un testigo del horror vivido.

El documental alcanzó una audiencia de 1.640 .000 espectadores, convirtiéndose en el programa más visto de la noche. Su impacto entre la población, difícil de mensurar, fue sin dudas grande: a diferencia de lo sucedido con el "show del horror", esta vez la descripción de la masacre dictatorial era respaldada por el Estado, que proponía una narrativa propia de la masacre dictatorial. En la enumeración -y posterior condena- de los múltiples crímenes de la represión, las voces de los afectados directos por la violencia estatal ocuparon un lugar protagónico (Crenzel, 2008; Feld, 2004). Fue esta decisión la producción del programa la que les permitió a los sobrevivientes de El Vesubio, por medio de la figura de Watts, dar a conocer su caso ante el país.

\section{Conclusiones}

El final de la dictadura favoreció la visibilización masiva de los crímenes de la represión. Cuando todavía no existía una explicación estatal sobre los secuestros, las torturas, las muertes y las desapariciones, fue la prensa gráfica la principal encargada de llevar adelante la difusión de los crímenes dictatoriales. Para ello, se valió del lenguaje que conocía, echando mano al sensacionalismo y la morbosidad. Mientras tanto, en la esfera gubernamental se debatía el modo adecuado de llevar adelante el juzgamiento de los responsables de la represión. En un intento por cumplir con esa promesa de campaña, Alfonsín lanzó un conjunto de medidas para avanzar en la investigación de las violaciones a los derechos humanos en el período 1976-1983. 
En este escenario, los sobrevivientes de El Vesubio desarrollaron un conjunto de iniciativas para denunciar los crímenes cometidos en ese CCD. En el plano judicial, sus declaraciones testimoniales fueron acompañadas por presentaciones ante los magistrados a cargo de la investigación, en las que los sobrevivientes demostraron no sólo su conocimiento de la represión dictatorial sino también su decisión de emplear las herramientas del derecho en su estrategia de denuncia. A estas acciones se sumaron, más allá de los tribunales, las manifestaciones públicas frente al lugar de cautiverio, los homenajes a los desaparecidos y las solicitadas de denuncia publicadas en los periódicos.

Estas acciones se desarrollaron en paralelo al fenómeno más amplio de la emergencia pública de los sobrevivientes: los medios de comunicación de la época y la propia CONADEP identificaron en ellos una fuente de información preciada sobre el dispositivo represivo. En el caso aquí analizado, la cobertura mediática osciló entre representar a los sobrevivientes como "denunciantes" de los crímenes dictatoriales y como meros productores de relatos sobre su experiencia de cautiverio. Esta ambivalencia en la forma de exhibir púbicamente su figura fue característica de los primeros meses de vida democrática.

Para los sobrevivientes de El Vesubio, quienes habían desarrollado una intensa actividad de denuncia en la etapa precedente, la posdictadura representó al mismo tiempo una oportunidad y un desafío. El final del régimen militar y el estímulo estatal a la investigación de los crímenes de la represión hizo posible desplegar la denuncia puertas adentro del país en un terreno más amplio y, sobre todo, más visible que durante la dictadura. Sin embargo, a la vez que ofreció nuevas posibilidades, el inicio de la democracia implicó también para los sobrevivientes el reto de su irrupción en la esfera pública: con las primeras representaciones mediáticas de la represión dictatorial inició también el proceso histórico de la construcción social de su figura, en un proceso que excedió en mucho al caso estudiado. El documental de la CONADEP marcó a la vez un hito y un rumbo en dicho proceso, resaltando la práctica testimonial de los sobrevivientes por sobre las demás facetas de su accionar. Los meses subsiguientes, con la publicación del Nunca más y la cobertura mediática del Juicio a las Juntas, no harían sino consolidar ese camino.

\section{Notas}

(1) La contraparte del Decreto 158/83 fue el 157/83, sancionado con anterioridad, a través del cual se disponía la persecución penal de las conducciones de las organizaciones político-militares. 
(2) Se entiende por posdictadura al período iniciado con la finalización del régimen militar. Concretamente, desde la asunción de Alfonsín, ocurrida el 10 de diciembre de 1983, a la presentación del informe de la CONADEP, en septiembre de 1984. Se trata de un período caracterizado por la inestabilidad del lenguaje y las categorías para hacer referencia al pasado inmediato y en el que diversos actores se enfrentan en el espacio público por instalarse como enunciadores legítimos de la "verdad" sobre ese pasado (Franco y Feld, 2015).

(3) El Vesubio fue uno de los más importantes centros clandestinos de detención bajo la órbita del Primer Cuerpo de Ejército. Estaba ubicado en el partido de La Matanza, en la zona oeste de la provincia de Buenos Aires, camino al aeropuerto internacional de Ezeiza. Junto al Ejército, participaron del entramado represivo articulado en torno a El Vesubio personal de la Policía de la provincia y del Servicio Penitenciario Federal. La investigación judicial en torno a los crímenes de El Vesubio acreditó el paso de 360 personas por ese CCD, de las cuales aproximadamente 150 fueron puestas en libertad, siendo el resto desaparecidas o asesinadas. Dado el carácter clandestino de la represión, las cifras están lejos de ser definitivas.

(4) Causa Nro. 35040/78, "Guarido, Paulino Alberto y Piñeiro, Mónica Haydée, s/privación ilegítima de la libertad", Juzgado Nacional de Primera Instancia en lo Criminal de Instrucción Nro. 3, Secretaría 110.

(5) El Partido de la Liberación, surgido con el nombre de Vanguardia Comunista, fue una organización de orientación maoísta surgida el 5 de abril de 1965. Su primer Secretario general fue Elías Semán, sucedido en el cargo en 1971 por Roberto Cristina. La investigación judicial por los crímenes de El Vesubio consigna sesenta secuestros de militantes del partido. De ese contingente, cuarenta personas salieron con vida. El resto continúa desaparecido.

\section{Bibliografía}

"Campo de detención y tortura". (10 de diciembre de 1983). La Gaceta, p. 4.

"Campo de detención". (10 de diciembre de 1983). La Razón, p. 14.

CONADEP (1984). Nunca más [programa de televisión].Buenos Aires.

Crenzel, E. (2008). Historia política del Nunca más. La memoria de las desapariciones en Argentina. Buenos Aires: Siglo XXI.

Crenzel, E. (2015). Ideas y estrategias de justicia ante la violencia política y las violaciones a los derechos humanos en la transición política en Argentina (1982-1983). En Feld, C. y Franco, M (comps.). Democracia, hora cero: actores, política y debates en los inicios de la posdictadura. Buenos Aires: FCE.

"Denuncia sobre un campo de detención clandestino". (30 de diciembre de 1983). La Prensa.

En CD "Centro Clandestino de Detención 'El Vesubio"'. Recuperado de http://www.memoriaenelmercosur.educ.ar/index094d.html?p=61

"Denunciaron la existencia de un campo de detención". (10 de diciembre de 1983). Tiempo Argentino. En CD "Centro Clandestino de Detención 'EI Vesubio". Recuperado de http://www.memoriaenelmercosur.educ.ar/index094d.html?p=61 
"Denuncian la ubicación de un campo de detención clandestino". (10 de diciembre de 1983). Clarín, p.22.

"Desnudan las atrocidades de un campo de concentración". (30 de diciembre de 1983). La Voz, p. 5.

"Denuncian localización de campo de detención y tortura camino a Ezeiza". (10 de diciembre de 1983). Crónica. En CD “Centro Clandestino de Detención “El Vesubio”. Recuperado de http://www.memoriaenelmercosur.educ.ar/index094d.html?p=61

"Denuncian más torturas". (30 de diciembre de 1983). Diario Popular, p. 6.

"Denuncian torturas en cárcel clandestina”. (29 de diciembre de 1983). Crónica, p.8.

Dürr, C. (2017). Memorias incómodas. El dispositivo de la desaparición y el testimonio de los sobrevivientes de los Centros Clandestinos de Detención, Tortura y Exterminio. Temperley: Tren en Movimiento.

Feld, C. (2004). La télévision comme scène de la mémoire de la dictature en Argentine. Une étude sur les récits et les représentations de la disparition forcée de personnes (Tesis doctoral). Université Paris 8.

Feld, C. (2014). ¿Hacer visible la desaparición?: las fotografías de detenidos-desaparecidos de la ESMA en el testimonio de Víctor Basterra. Clepsidra. Revista interdisciplinaria de estudios sobre memoria, 1.

Feld. C y Franco, M. (2015). Democracia y derechos humanos en 1984, ¿hora cero? En Feld, C. y Franco, M (comps.). Democracia, hora cero: actores, política y debates en los inicios de la posdictadura. Buenos Aires: FCE.

Feld, C. y Messina, L. (2014). En torno a la palabra testimonial de los sobrevivientes: testigos legitimados y denegados de los centros clandestinos de detención en Argentina. Tramas, 41.

Franco, M. (2012). Un enemigo para la nación. Orden interno, violencia y "subversión", 19731976. Buenos Aires: FCE.

Franco, M. (2015). La teoría de los dos demonios en la primera etapa de la posdictadura. En Feld, C. y Franco, M (comps.). Democracia, hora cero: actores, política y debates en los inicios de la posdictadura. Buenos Aires: FCE.

Forcinito, A. (2012). Los umbrales del testimonio. Entre las narraciones de los sobrevivientes y las señas de la posdictadura. Madrid: Iberoamericana.

González Tizón, R. (2016). 'Cada voz que se alce puede salvar una vida en Argentina'. La producción testimonial de los sobrevivientes de los Centros Clandestinos de Detención 
en el marco de la Comisión Argentina por los Derechos Humanos (1979-1983). Papeles de Trabajo, 10(17), pp. 162-183.

"Hallan un campo de detención clandestino en La Matanza". (10 de diciembre de 1983). Diario Popular. En CD "Centro Clandestino de Detención 'El Vesubio'”. Recuperado de http://www.memoriaenelmercosur.educ.ar/index094d.html?p=61

Juzgado Penal 7 (1983). Causa Nro. 1.800/83. "Armando Benet, Titular de la Fiscalía n² s/denuncia", Secretaría Nro. 13, provincia de Buenos Aires.

Landi, O. y González Bombal, I. (1995). Los derechos en la cultura política. En Acuña C. H et al. Juicio, castigo y memorias. Derechos humanos y justicia en la política argentina. Buenos Aires: Nueva Visión.

Longoni, A. (2007). Traiciones. La figura del traidor en los relatos acerca de los sobrevivientes de la represión. Buenos Aires: Norma.

"Piden se investiguen secuestros, torturas y crímenes cometidos en un campo de detención". (29 de diciembre de 1983). La Razón. En CD "Centro Clandestino de Detención 'El Vesubio"”.

de http://www.memoriaenelmercosur.educ.ar/index094d.html?p=61

"Piden investigar un centro de detención en La Matanza". (30 de diciembre de 1983). Crónica. En CD "Centro Clandestino de Detención 'El Vesubio". Recuperado de http://www.memoriaenelmercosur.educ.ar/index094d.html?p=61

Rama, C. (2017). La revinculación como problemática del proceso de reaparición de los sobrevivientes de los centros clandestinos de detención en Buenos Aires. Revista de Historia, 18, Facultad de Humanidades, Universidad Nacional del Comahue.

Messina, L. (2012). Reflexiones en torno a la práctica testimonial sobre la experiencia concentracionaria en Argentina. Sociedad y economía, 23.

“Nunca más". (29 de septiembre de 1984). Clarín. En CD "Centro Clandestino de Detención “El Vesubio"'. http://www.memoriaenelmercosur.educ.ar/index094d.html?p=61

Rupar, B. (2016). A emêrgencia do Maoismo na Argentina: uma aproximaçao através de Vanguardia Comunista e o Partido Comunista Revolucionario (tesis de Maestría). Universidad Federal Fluminense.

Tello, M. (2015). Yo acuso: un análisis antropológico sobre lo jurídico en los primeros testimonios sobre 'La Perla'. Clepsidra, 4, octubre.

“Torturaban en cárcel ilegal”. (30 de diciembre de 1983). Clarín, p. 7. 
Vezzetti, H. (2002). Pasado y presente. Guerra, dictadura y sociedad en la Argentina. Buenos Aires : Siglo XXI. 